\title{
The Phantom Decoy Effect on Hotel Room Selection: Impact on choice and perception
}

\author{
Jeffrey A. Beck \\ Associate Professor \\ The School of Hospitality Business \\ Michigan State University \\ USA \\ Feitong Li \\ The School of Hospitality Business \\ Michigan State University \\ USA
}

\section{ABSTRACT}

When faced with two similar alternatives, customers struggle to choose one. The concept of a phantom decoy, an attractive but unavailable alternative in the list of choices at the final purchasing stage, may help customers make the choice that best serves the customer and the hotel. Hotel rooms are not always available due to popularity or renovation. In this study, a $2 \times 2$ experiments was designed to investigate whether a phantom decoy would influence the decision-making behavior of people when they choose hotels, and to test the satisfaction between booking a hotel room using an online travel agent (OTA) and the hotel brand website. Reactance theory and attribution theory were confirmed when a phantom decoy was added to customers' choice sets.

\section{KEYWORDS: phantom decoy; knowledge; attribution; OTA; hotel official website; purchasing intention INTRODUCTION}

Most decision-making research focuses on the inclusion of specific alternatives in a choice set that are used to alter a customer's purchase intentions among all the alternatives in the choice set. Those specific alternatives are typically called decoys. A large amount of research has demonstrated that decoys have a significant impact on triggering different choices. (e.g., Choplin \& Hummel, 2005; Dhar \& Glazer, 1996; Huber, Payne, \& Puto, 1982; Scarpi \& Pizzi, 2013; Sheng, Parker, \& Nakamoto, 2005; Simonson, 1989; Simonson \& Tversky, 1992). For example, a consumer might struggle to make a choice when faced with two undistinguishable alternatives. However, they are more likely to choose the alternative that includes a decoy instead of the one without a decoy. There are two types of decoys that have been used in previous studies; symmetrically dominated decoys and asymmetrically dominated decoys (Ariely \& Wallsten, 1995; Huber, Payne, \& Puto, 1982). Asymmetrically dominated decoys are defined as a decoy alternative that has the same level as the dominating alternative in one attribute but the lower level in the other attribute, while symmetrically dominated decoy is dominated by both indifferent alternatives. However, this study focuses on the concept of phantom decoy, which was first introduced by Pratkanis and Farquahar (1992). Phantom decoy refers to an attractive alternative in the choice set but unavailable at the time when people make choice. For example, a better product is out-of-stock or sold out.

The hotel room, the main product of hotels, can be sold out at a certain period. People might be indifferent or struggle to choose between two alternatives. However, if a phantom decoy was added, they might make their decisions more easily and quickly. Furthermore, it is necessary to know whether the unavailability of the hotel could impact customers' attitudes and purchase intentions. Nonetheless, no one has attempted to apply phantom decoy in the hotel industry study. Thus, it is truly meaningful for hospitality researchers to research on phantom decoys. To fill in the gap, this article would try to test whether the phantom decoy would influence the decision-making behavior of people when they choose hotels on OTA and hotel websites. 


\author{
E-ISSN: 2469-6501 \\ VOL: 6, ISSUE: 1 \\ January/2020 \\ DOI:10.33642/fjbass.v6n1p1 \\ https://ijbassnet.com/
}

\title{
LITERATURE REVIEW
}

\section{Traditional Decoy Types}

The first type of decoy alternative is asymmetrically dominated decoy. Huber, Payne, \& Puto (1982) examined the effect of asymmetrically dominated decoy alternative, which is dominated by only one of the whole alternatives on all attributes. Customers might pay more attention to the dominating alternative that contains asymmetrically dominated decoy than other alternatives. The second type of decoy alternative is symmetrically dominated decoy, which is dominated by all alternatives on all attributes. (Wedell \& Pettibone,1996) Both asymmetrically and symmetrically dominated decoys are inferior to dominating alternatives. However, the third type of decoy alternative, viable decoy, is not dominated by all existing alternatives. (Huber \& Puto, 1983) This decoy has slight advantages compared with one alternative on one attribute, but many more disadvantages on the other attribute. Thus, a viable decoy still has a close relationship with a certain alternative. It could help such an alternative to catching customers' attention.

\section{Phantom Decoy Types}

In past studies, there are two ways to categorize phantom decoy. They are location and knowledge. First, phantom decoys can be categorized based on the distance between the target alternative and themselves. Close phantom means that it is a little bit more attractive than the target's greatest dimension, while far phantom is much more attractive than the target's best dimension (Pettibone \& Wedell, 2007). Second, phantom decoys can be classified according to customers' knowledge about the unavailability (Pizzi \& Daniele, 2013, Pratkanis \& Farquhar, 1992), which is applied in this study. Known phantom means that it is shown as unavailable at the beginning, but unknown phantom refers that customers would notice the unavailability when they intend to purchase the product.

The study adopted the rage phantom decoy in Pettibone and Wedell research (2007). The value of $\mathrm{T}$ (the target) is superior to C (the competitor) on Dimension 2 but not on Dimension 1. (Pizzi \& Daniele, 2013) In this study, location and price were chosen to dimension. Baskey and Labagh (1992) found that both location and price were highly concerned with customer satisfaction. In addition, Martín-Ruiz, Barroso-Castro, and Rosa-Díaz (2012) also stated that price fairness was an important factor for customers when they chose hotels. In the study, hotel A was set as a targeted hotel, hotel B was the competitor hotel, and hotel $\mathrm{C}$ was the phantom decoy. Thus, hotel $\mathrm{A}$ has a good price but inconvenient location, whereas the hotel B product has a great location but a high price.

Phantom decoy is the alternative that extends the target's popular dimension and keeps the same level of the other dimension. It represents phantom decoy in the study. In contrast with hotel A, hotel C has a little lower price but the same level of location. However, known phantom and unknown phantom have no difference in the position in the attribute area. In other words, the only difference between the known phantom decoy and the unknown phantom decoy is when the unavailability is displayed to customers. (Pizzi \& Daniele, 2013)

\section{Theories of Decision-making}

Brock (1968) first claimed that the value of the commodity would increase if it were not available or hard to get in his commodity theory. Pratkanis \& Farquhar (1992) stated the principle of scarcity attractiveness. They found that customers perceive the unavailable commodity more attractive. According to such a theory, the phantom decoy could be more attractive than existing products. In other words, since phantom decoy dominates target on price, they would emphasize more perceived attractiveness of price. Furthermore, the known phantom is perceived unavailable from the beginning. Then, customers might be influenced by the scarce product information. They would evaluate the known phantom more attractive and also emphasize the perceived attractiveness of price.

Therefore, the following hypotheses are proposed:

Hypothesis 1a: Hotel C would increase the customer attitude towards hotel A over hotel B.

Hypothesis 1b: Hotel C would increase the customer purchasing intention for hotel A over hotel B.

Hypothesis 2a: Unavailability of hotel $\mathrm{C}$ shown at the beginning could bring a larger increase in the customer attitude towards hotel A over hotel B than the unavailability of hotel $\mathrm{C}$ shown at the end of purchasing. 


\author{
E-ISSN: 2469-6501 \\ VOL: 6, ISSUE: 1 \\ January/2020 \\ DOI:10.33642/fjbass.v6n1p1 \\ https://ijbassnet.com/
}

Hypothesis 2b: Unavailability of hotel $\mathrm{C}$ shown at the beginning could bring a larger increase in the customer purchasing intention for hotel A over hotel B than the unavailability of hotel C shown at the end of purchasing.

Brehm (1966) first proposed reactance theory, which stated that people might act a reverse way to what they originally want to do if they feel a threat to their behavioral freedom. (Baumeister, Catanese, \& Wallace, 2002, Pizzi \& Daniele, 2013) Phantom decoy is a kind of threat to customers' behavioral freedom since it limits the potential options for choice. More specifically, the phantom alternative would let the competitor looks more attractive than the target. In addition, the unknown phantom decoy is only shown at the stage of the purchasing process. Such phantom decoy would cause greater reactance than known phantoms, as the previous expectations terminate suddenly and unexpectedly during the purchasing time.

Therefore, the following hypotheses are proposed:

Hypothesis 3a: Hotel C would increase the customer attitude towards hotel B over hotel A.

Hypothesis $3 \boldsymbol{b}$ : Hotel $\mathrm{C}$ would increase the customer purchasing intention for hotel B over hotel A.

Hypothesis 4a: Unavailability hotel $\mathrm{C}$ shown at the end of purchasing could bring a larger increase in the customer attitude towards hotel B over hotel A than the unavailability of hotel C shown at the beginning.

Hypothesis $\mathbf{4 b}$ : Unavailability hotel $\mathrm{C}$ shown at the end of purchasing could bring a larger increase in the customer purchasing intention for hotel B over hotel A than unavailability of hotel $\mathrm{C}$ shown at the beginning.

As information technology develops at a fast speed, hotel booking channel changes as well. The multi-channel distribution that combines traditional and modern booking channels, electric channel, is used by hotel managers to sell hotel rooms (Morosan\&Jeong,2008). In recent years, both OTA and hotel official websites are the most popular ways for the customer to book hotel rooms. Selling hotel rooms on the official website is the first choice of most hotels. However, OTA is a more efficient way for a hotel to sell rooms (Toh et al., 2011).

Weiner (1986) applied attribution theory in customer behavior research by stating that locus of causality, controllability, and stability were three main dimensions to evaluate attribution theory. Locus of causality concentrates on who causes the failure, such as customers themselves, companies, or unpredictable environment effects. Controllability means whether companies could control or avoid failure. Stability refers to how long the failure would last. Tsiros, Mittal, \& Ross (2004) announced that responsibility was applied in attribution theory research in recent studies since some connection between locus of causality and controllability existed. In addition, Iglesias (2009) found that if the service failure attributed to companies, instead of other external causes, customer satisfaction would be less as well.

Therefore, the following hypotheses are proposed:

Hypothesis 5: If unavailability was showed on the OTA website, customer's satisfaction of booking choice would be a little less under unknown condition than under known condition

Hypothesis 6: If unavailability showed on hotel official website, customer's satisfaction with booking choice would be much less under unknown conditions than under known conditions.

Customer satisfaction, attitude, and purchasing intention would be measured in this study. Information satisfaction could influence a customer's overall satisfaction (Spreng, MacKenzie \& Olshavsky, 1996). Even though booking page that contains the information of unavailability of the hotel could have the possibility to make customers unhappy, different booking channel would have different effects. In addition, negative emotions could affect the personal evaluation of hotels. Attitude is another factor to be measured. If customers hold negative attitudes toward the hotel they choose, their willingness of purchasing could decrease, since some researchers found that customers tend to pay more attention to negative rather than positive information (Fiske, 1980; Skowronski \& Carlston,1989). Purchasing intention is applied to evaluate whether phantom decoy could let customers book rooms in one hotel when customers face two indifferent hotels. In addition, perceived control was controlled in this study as it could make a positive influence on customers' mental happiness (Noone, 2008; Hui \& Bateson, 1991). The frequency of staying a hotel was also controlled in this study, since the experience of booking or living in a hotel could influence people's booking behaviors.

\title{
Methodology
}




\section{Participants and Design}

One hundred and fifty students at Michigan State University participated in this study. 128 of them were valid. The functional response rate for the study was nearly 85 percent. All the participants are college $(\mathrm{N}=7)$ or undergraduate students $(\mathrm{N}=121)$. Of the participants, 38.3 percent were male $(\mathrm{N}=49)$ and 61.7 percent were female $(\mathrm{N}=79)$. Approximately 85 percent of participants were from 20 to 23 years $(\mathrm{N}=110)$ and 15 percent were 24 years or older $(\mathrm{N}=18)$. Participants were randomly assigned to one of four conditions in a 2 (phantom knowledge: known or unknown) $\times 2$ (booking channel: OTA or hotel website) between-participants factorial design.

\section{Procedure}

A research participant information and consent form were shown at the beginning of the study. Participants learned that the study was related to consumer choice of hotels. Various tasks exist in the study, including reading a scenario and answering questions on a survey. Following those introductions, all participants were instructed that they were planning a trip to a major city in the United States. They had narrowed their choice to three hotels, A, B, and C. while B has a better location than A. Hotel $\mathrm{C}$ has the same location as A and a lower price than A, which is ideal. When participants finished reading the scenario, they were asked to complete measures of booking intention, the satisfaction of choice and attitude towards hotels.

\section{Independent Variables}

Knowledge of Phantom Decoy. According to random assignment, the knowledge of phantom decoy was either known or unknown. In the known condition, the scenario was described as you choose to select a room anyway. However, the room you selected is in fact unavailable. In contrast, in the unknown condition, the scenario was described as you decide to go ahead with your purchase. Right before you finalize the purchase, you find that the room you selected is in fact unavailable.

Booking Channel. Participants were also randomly assigned to booking channel, either OTA or hotel website. In the OTA condition, the scenario was shown that As you are about to purchase Hotel $C$, you notice that on the OTA web page that some rooms are sold out. In the hotel website condition, as you are about to purchase Hotel C, you notice that on the hotel official web page that some rooms are sold out.

\section{Dependent Measures}

Booking Intention. Participants used seven-point Likert scales, ranging from 1 (strongly disagree) to 7 (strongly agree), to indicate their agreement or disagreement of the willingness of booking hotel B with following instructions, adapted from Chiang \& Jang (2006) and Leung, Bai, \& Stahura (2013).

1. My willingness to book hotel A is very high.

2. The probability that I would consider booking hotel A is very high.

3. The likelihood of booking hotel A is very high.

Scores were averaged to derive the booking intention measure. The Cronbach's reliability of this measure was .91.

Satisfaction. To measure the satisfaction of choice, participants used seven-point Likert scales, ranging from 1 (strongly disagree) to 7 (strongly agree), to indicate agreement or disagreement with the following four items:

\section{I am satisfied with my choice}

2. I am pleased with my choice

3. I am contented with my choice

4. I am delighted with my choice

Items were adapted from Spreng, MacKenzie, \& Olshavsky (1996); Iglesias (2009).

The reliability of Cronbach's alpha for this measure was .93. Scores were averaged to form a composite index.

Attitude. Following satisfaction measure, participants rated attitude towards both hotel A and hotel B. Responses, provided on scales ranging from 1 (bad, unfavorable, dislike, negative impression) to 7 (good, favorable, like, positive impression), were highly reliable (Cronbach alpha $=.95)$ and were averaged to form a composite index.

Items were adapted from Karmakar \& Tormala (2010); Lee \& Cranage (2014). 


\section{Control Variables}

The frequency of stay in a hotel was applied as a control variable in this study. Participants reported relatively frequent stay in hotels, as indicated by the mean response of $4.16(\mathrm{SD}=1.59)$ to how often they stay in hotels on a seven-point Likert scale (where 1= 'Very rare' to 7= 'Very often'). Another control variable is a single item in perceived control measure (I faced very high barriers in choosing a hotel). Participants used a seven-point Likert scale to describe barriers, ranging from 1 (strongly disagree) to 7 (strongly agree) (Bansal \& Taylor, 2002).

\section{Manipulation Check Variables}

To test whether the manipulation of different levels of phantom decoy knowledge and hotel booking channel were noticed by participants, participants used seven-point Likert scales, ranging from 1 (strongly disagree) to 7 (strongly agree), to describe the level of agreement with the following four items:

1. In the scenario, hotel $C$ is the most ideal choice.

2. Hotel $C$ is sold out due to popularity.

3. You were booking a hotel on OTA.

4. You were booking a hotel on the hotel website.

These items were displayed to participants at the end of the survey.

\section{Results}

Manipulation check. A series of one-way repeated measure ANOVAs was conducted to evaluate the manipulations. All the results showed a significant difference in an expected way. Participants exposed to OTA conditions gave a higher score in the manipulation check item that you were booking a hotel on OTA $(\mathrm{M}=5.84)$ than participants exposed to hotel website conditions $(\mathrm{M}=4.31)(\mathrm{F}(76,212)=45.25, \mathrm{P}<.001)$. By contrast, participants exposed to hotel website conditions gave a higher score in the manipulation check item that you were booking a hotel on the hotel website $(\mathrm{M}=4.60)$ than participants exposed to OTA conditions $(\mathrm{M}=3.67)(\mathrm{F}(27,428)=8.15, \mathrm{P}<.05)$.

Booking intention. An ANCOVA on the willingness of booking hotel B index had no main effect. Neither knowledge of phantom decoy or booking channel nor the knowledge of phantom decoy $\times$ booking channel interaction approached significance $(\mathrm{P}>.1)$. Thus, phantom decoy does not influence customers purchasing intentions. Consequently, hypotheses $1 \mathrm{~b}$, $2 b, 3 b$, and $4 b$ were not supported (Table 1$)$.

\begin{tabular}{|l|l|c|c|c|}
\hline \multicolumn{5}{|c|}{$\begin{array}{c}\text { ANCOVA with Booking Intention as the Dependent Variable and Knowledge of Phantom Decoy } \\
\text { and Booking Channel as the Independent Variables }\end{array}$} \\
\hline & \multicolumn{2}{|c|}{ Known Phantom } & Unknown Phantom \\
\hline & OTA & Hotel Website & OTA & Hotel Website \\
\hline Booking Intention & & 4.98 & 5.32 & 5.01 \\
\hline Mean & 4.79 & 1.25 & 1.08 & 1.23 \\
\hline SD & 0.88 & Table 1
\end{tabular}

Attitude. An ANCOVA on the attitude towards hotel B index yielded a marginally significant effect of the knowledge of phantom decoy $(\mathrm{F}(1,122)=3.72, \mathrm{P}<.07)$; participants under unknown conditions held higher attitudes toward hotel $\mathrm{B}(\mathrm{M}$ $=5.54)$ than participants under known conditions $(\mathrm{M}=5.17)$. Neither booking channel nor knowledge of phantom decoy $\times$ booking channel interaction approached significance $(\mathrm{P}>.1)$ Thus, phantom decoy could increase customer attitude towards competitors rather than the target. Consequently, hypotheses 1a and $2 \mathrm{a}$ were not supported, but hypotheses $3 \mathrm{a}$ and $4 \mathrm{a}$ were supported (Table 2). 


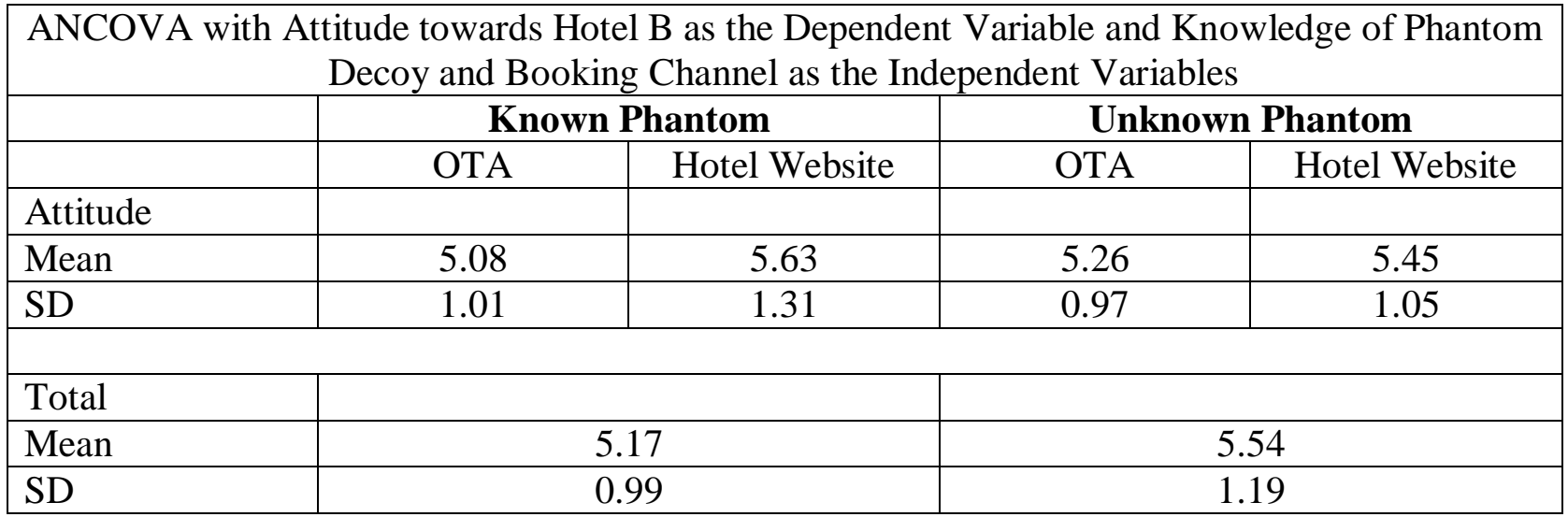

Table 2

Satisfaction. An ANCOVA on the satisfaction of choice index yield a significant knowledge of phantom decoy by booking channel interaction $(\mathrm{F}(1,122)=4.48, \mathrm{P}<.05)$. Under the known condition, customer satisfaction is a litter lower when booking on OTA $(\mathrm{M}=4.76)$ rather than the hotel official website $(\mathrm{M}=4.94)$. By contrast, under unknown conditions, customer satisfaction is higher when booking on OTA $(\mathrm{M}=5.49)$ rather than the hotel official website $(\mathrm{M}=5.01)$. In addition, satisfaction of choice index yielded a marginally significant effect of the knowledge of phantom decoy $(\mathrm{F}(1,122)=4.84, \mathrm{P}<$ .05); participants under unknown conditions held higher satisfaction $(\mathrm{M}=5.54)$ than participants under known conditions $(\mathrm{M}=$ 5.17). Booking channels did not approach significance (P > .1). Thus, hypotheses 5 and 6 were not supported (Table 3).

\begin{tabular}{|l|l|c|c|c|}
\hline \multicolumn{4}{|c|}{ ANCOVA with Satisfaction as the Dependent Variable and Knowledge of Phantom Decoy and } \\
Booking Channel as the Independent Variables
\end{tabular}

Table 3

\section{Discussion}

The result showed that the customer's attitude towards hotel B was higher than hotel A. In other words, the phantom decoy could increase the customer's attitude towards competitor products than the target product. Meanwhile, the unknown phantom decoy brought more effects on customer's attitudes than a known phantom decoy. Customers do not prefer that their expectation terminated unpredictably. Thus, when the truth of unavailability was only displayed at the final purchasing stage, customers were more likely to choose the competitor's product instead of the target product. In addition, the result indicated that purchasing intention was not supported by either theory. Even though people held a better attitude towards hotel B than hotel A, they were still not willing to book rooms in hotel B. It is because that attitude and purchasing intention are two different perception stages. A good attitude would not bring purchasing behavior as a result of any time. Phantom decoy could have already hurt people's intention of purchasing. The best product is not available. Even though a substitute is provided, it's still not the product that customers intend to choose. They might have good attitudes toward the substitute but not purchase that product. Hypotheses $5 \& 6$ were not supported in the experiment, but the attribution theory was support. Interaction effects showed that people's satisfaction was different when they faced phantom decoy on a different website, OTA and hotel. Customers might feel no different between OTA and hotel websites as the best product was not available. Moreover, customers could hold positive opinions for hotel official website, since the hotel showed unavailability at the beginning, which could be 


\author{
E-ISSN: 2469-6501 \\ VOL: 6, ISSUE: 1 \\ January/2020 \\ DOl:10.33642/fjbass.v6n1p1 \\ https://ijbassnet.com/
}

an honest behavior. As a result, the difference of satisfaction between OTA $(M=4.76)$ and hotel website $(M=4.94)$ was not large and the mean value of the hotel website was even higher under known condition. However, under unknown conditions, customer held higher satisfaction when booking on OTA $(\mathrm{M}=5.49)$ rather than hotel website $(\mathrm{M}=5.01)$. The unavailability shown at the final purchasing stage could be a strike to customers who book on the official website because they had to search other substitutes on either OTA or other hotel websites at that time. By contrast, customers booking on the OTA website could easily find substitutes, as several substitute hotels might have already been listed at the end of the booking page. Thus, the study demonstrated that OTA was an important distribution channel for hotels.

\title{
Implications
}

This study first tried to apply the concept of phantom decoy to the hotel industry. None of the previous studies provide a connection between phantom decoy and hotels. Price and location are both important factors when people select hotels. When customers are struggling to choose hotels, the phantom decoy could guide people to make the decision. In addition, three different theories concerning customer choice were used to predict customer's perceptions and choices. Only reactance theory works well in predicting customer perception. However, such theory indicated that customers would choose a competitor if phantom decoy was added. Hotel managers should pay attention to set phantom decoy by accident. For example, the unavailability was caused by website bugs. They should update and maintain their hotel information systems regularly. In addition, hotel managers should recognize the importance of OTA as people hold more tolerance for unknown phantom decoy shown on OTA rather hotel official website. Thus, OTA is not just a distribution channel to help hotels to sell their rooms, but a useful buffer to help hotel managers to control the risks and minimize losses. Moreover, if unavailable rooms happened because of renovation or other events, hotel managers should avoid showing those rooms on the booking page, especially showing after customers submit their orders. The reason is that such rooms could be natural phantom decoys that bring negative effects of other rooms in the hotel, as those available rooms not only decrease customers' attitudes and purchasing intention toward the hotel, but also make customers dissatisfied with their choices. The much worse effect is that customers might lose confident about the hotel itself.

\section{Limitation and future research}

The experiment is a scenario-based study. The process was that participants read the scenario and then finished surveys. They were not in a real booking environment. The involvement of the texted survey would be lower than the real environment field study. Secondly, the study used student samples in the experiment. Homogeneous sample, age, education, and household income make it difficult to extend the findings to the general customers. Another limitation is that the current study is a cross-functional one. The study only tests the first-time effect of phantom decoy instead of doing longitudinal researches. When facing phantom decoys two or more times, customers' perception and choice could change. The last limitation is that the reliability of the control scale is not high. In this study, only the third item of control was used as the covariate. Thus, for future study, a real booking webpage might be designed to make participants more involved in the booking situation. Secondly, a general sample could be chosen to analyze the general effects of phantom decoy in the hotel booking process. Moreover, future research could try to find the second time effects of phantom decoy and the measure items for one scale should be consistent. Future researchers could investigate the effects of phantom decoy when applying other theories concerning customer choice. They could also test the effects of phantom decoy in one hotel, which means that all target, competitor, and phantom decoy products are different types of rooms in the same hotel.

\section{References}

Ariely, D., \& Wallsten, T. (1995). Seeking subjective dominance in multidimensional space: an explanation of asymmetric effect. Organizational Behavior and Human Decision Process, 63(3), 223.

Bansal, H.S., \& Taylor, S.F. (2002). Investigating interactive effects in the theory of planned behavior in a serviceprovider switching context. Psychology and Marketing, 19(5), 407-425.

Barsky, J. D., \& Labagh, R. (1992). A strategy for customer satisfaction. Cornell Hotel and Restaurant Administration Quarterly, 33(5), 32. 


\author{
E-ISSN: 2469-6501 \\ VOL: 6, ISSUE: 1 \\ January/2020 \\ DOI:10.33642/fjbass.v6n1p1 \\ https://ijbassnet.com/
}

Baumeister, R. F., Catanese, K. R., \& Wallace, H. M. (2002). "Conquest by force.” Review of General Psychology, 6, 92-1 Brehm, J. W. (1966). A theory of psychological reactance. New York: Academic Press.

Brock, T. C. (1968). Implications of commodity theory for value change. In A. G. Greenawalt. C. Brock, \& T. M. Ostrom (Eds.), Psychological foundations of attitudes (pp. 243-275). New York: Academic.

Chiang, C., \& Jang, S. (2006). The effects of perceived price and brand image on value and purchase intention: Leisure travelers' attitudes toward online hotel booking. Journal of Hospitality \& Leisure Marketing, 15(3), 49-69

Choplin, J., \& Hummel, J. (2005). Comparison-induced decoy effects. Memory \& Cognition, 33(2), 332-343.

Dhar, R., \& Glazer, R. (1996). Similarity in context: Cognitive representation and violation of preference and perceptual invariance in consumer choice. Organizational Behavior and Human Decision Processes, 67(3), 280-293.

Fiske, S. T. (1980). Attention and weight in person perception: The impact of negative and extreme behavior. Journal of Personality and Social Psychology, 38(6), 889-906.

Huber, J., Payne, J. W., \& Puto, C. (1982). Adding asymmetrically dominated alternatives: Violations of regularity and the similarity hypothesis. Journal of Consumer Research, 9(1), 90-98.

Huber, J., \& Puto, C. (1983). Market boundaries and product choice: Illustrating attraction and substitution effects. Journal of Consumer Research, 10, 31-44.

Hui, M. K., \& Bateson, J. E. (1991). Perceived control and the effects of crowding and consumer choice on the service experience. Journal of Consumer Research, 18(2), 174-184.

Iglesias, Victor. "The Attribution of Service Failures: Effects on Consumer Satisfaction.” The Service Industries Journal 29.2 (2009): 127-141.

Karmarkar, U.R., \& Tormala, Z.L. (2010). Believe me, I have no idea what I'm talking about: The effects of source certainty on consumer involvement and persuasion. Journal of Consumer Research, 36(6), 1033-1049

Lee, C. H., \& Cranage, D. A. (2014). Toward understanding consumer processing of negative online word-of-mouth communication: The roles of opinion consensus and organizational response strategies. Journal of Hospitality \& Tourism Research, 38(3), 330.

Leung, X. Y., Bai, B., \& Stahura, K. A. (2013). The marketing effectiveness of social media in the hotel industry: A comparison of Facebook and Twitter. Journal of Hospitality \& Tourism Research, doi: 1096348012471381.

Martin-Ruiz, D., Barroso-Castro, C., \& Rosa-Diaz, I. (2012). Creating customer value through service experiences: An empirical study in the hotel industry. Tourism and Hospitality Management, 18(1), 37-53.

Morosan, C., \& Jeong, M. (2008). Users' perceptions of two types of hotel reservation web sites. International Journal of Hospitality Management, 27(2), 284-292.

Noone, B. M. (2008). Customer perceived control and the moderating effect of restaurant type on evaluations of restaurant employee performance. International Journal of Hospitality Management, 27(1), 23-29

Pettibone, J. C., \& Wedell, D. H. (2007). "Testing alternative explanations of phantom decoy effects.” Journal of Behavioral Decision Making, 20(3), 323-341.

Pratkanis, A. R., \& Farquhar, P. H. (1992). "A brief history of research on phantom alternatives: Evidence for seven empirical generalizations about phantoms." Basic and Applied Social Psychology, 13(1), 103-122.

Scarpi, D., \& Pizzi, G. (2013). The impact of phantom decoys on choices and perceptions. Journal of Behavioral Decision Making, 26(5), 451.

Sheng, S., Parker, A. M., \& Nakamoto, K. (2005). Understanding the mechanism and determinants of compromise effects. Psychology and Marketing, 22(7), 591-609.

Simonson, I. (1989). Choice based on reasons: The case of attraction and compromise effects. Journal of Consumer Research, $16,158-174$. 
Simonson, I., \& Tversky, A. (1992). Choice in context: Tradeoff contrast and extremeness aversion. Journal of Marketing Research, 29(3), 281-295.

Skowronski, J. J., \& Carlston, D. E. (1989). Negativity and extremity biases in impression formation: A review of explanations. Psychological bulletin, 105(1), 131.

Spreng, R. A., MacKenzie, S. B., \& Olshavsky, R. W. (1996). A reexamination of the determinants of consumer satisfaction. Journal of Marketing, 60(3), 15-32.

Toh, R. S., Raven, P., \& DeKay, F. (2011). Selling rooms: Hotels vs. third-party websites. Cornell Hospitality Quarterly, 52(2), 181.

Trueblood, J. S., \& Pettibone, J. C. (2017). The phantom decoy effect in perceptual decision making. Journal of Behavioral Decision Making, 30(2), 157-167.

Tsiros, M., Mittal, V., \& Ross, W.T., Jr. (2004). “The role of attributions in customer satisfaction: A reexamination.” Journal of Consumer Research, 31(2), 476-483.

Weiner, B. (1986). An attributional theory of motivation and emotion. New York: Springer. 